Check for updates

Department of Primary Care and Public Health, Imperial College London

2 Chelsea and Westminster Hospital NHS Trust

3 Children's neurosciences, Evelina London Children's Hospital, London

4 Department of Women and Children's Health, Faculty of Life Sciences and Medicine, King's College London

Cite this as: BMJ 2021;375:n2711 http://dx.doi.org/10.1136/bmj.n2711 Published: 05 November 2021

\section{The failure of provision for neurodiverse children during the covid-19 pandemic}

\author{
Rakhee Shah, ${ }^{1,2}$ Michael Absoud,
}

The indirect effects of the covid-19 pandemic threaten to have a substantial and long-lasting negative impact on children and young people's physical and mental health. Some have been disproportionately affected by containment policies such as social distancing, repeated isolation of school bubbles, and closure of schools. One such group are those children and young people with neurodevelopmental conditions such as Autism Spectrum Disorder (hereafter, autism) whose unique needs have been highlighted by the BMJ's Best Practice recent review. ${ }^{1}$ As this group lacks representation in policy spheres, and as the UK "learns to live with covid," their specific needs have been failed.

\section{Impact of the pandemic on the health and behaviour of children and young people with autism}

Autism is a lifelong neurodevelopmental condition with impairments in a dyad of features on a dimensional spectrum, characterised by difficulties in social communication, restricted interests, repetitive behaviours, and sensory behaviours. ${ }^{1}$ In addition to these central features, up to $70 \%$ of children and young people with autism can have at least one co-occurring mental health diagnosis. ${ }^{2}$ Children and young people with autism experienced specific additional health challenges as a result of covid-19 restrictions, which led to disruption of routines and structure, which they normally rely on. ${ }^{3}$ In addition to the increased uncertainty and lost educational support, the significant reduction in respite, therapy, social care, and after school support posed additional threats for vulnerable families. ${ }^{4}$

Seventy five percent of 2000 children with autism that were surveyed by Ambitious about Autism in 2021, reported that they were feeling more anxious than before the covid-19 pandemic. ${ }^{5}$ Parents of children and young people with autism also reported increase in behaviours such as increase in stereotypies, hypersensitivity, aggression, changes in appetite, poor sleep, and tics. ${ }^{6}$

The number of routine and urgent child and adolescent eating disorder service referrals in the UK have almost doubled in the past year. ${ }^{7}$ It is thought that a large percentage of referrals are due to Avoidant/Restrictive Food Intake Disorder (ARFID) with autism and associated with worsening nutritional adequacy. ${ }^{8}$ Increased anxiety and the need to control, may have worsened restrictive eating behaviours among children and young people with autism. $^{9}$

Children and young people with autism often have additional physical, sensory, and behavioural needs such as epilepsy, hypersensitivity to stimuli, difficulties with sleep and toileting, which may require input from specialist nurses, hospital services, and routine medical and therapy input in school. Many paediatric outpatient and child and adolescent mental health services had to halt face-to-face appointments during the covid-19 pandemic, which has left several children with autism with unmet health needs. Waiting lists for an assessment for autism are one of the longest among any specialty/condition in the country. It is estimated that 128 ooo children and young people with suspected autism are facing even longer delays for diagnostic assessment, as a result of the pandemic. ${ }^{10}$ Delays in diagnosis of autism lead to missed early intervention and parent mediated support. ${ }^{6}$

Approximately $30 \%$ of children and young people with autism will also have a learning disability (LD). ${ }^{11}$ Before the covid pandemic children and young people with learning disability were more likely to live in poverty, a situation that has been made worse by the covid-19 pandemic, exacerbating health inequalities. ${ }^{12}$

\section{Unequal access to education}

Education is a social determinant of health, particularly in those with special educational needs. Many children and young people with autism receive additional educational support in the form of specially designed plans to meet their educational needs. Virtual teaching methods were not specifically adapted for their needs. In a survey carried out by the National Autistic Society, seven out of 10 parents reported their child has had difficulty understanding or completing school work and around half said their child's academic progress was suffering. ${ }^{13}$ When schools reopened, $72 \%$ of Special Educational Needs Coordinators reported that they struggled to support children with their Education, Health and Care plans. ${ }^{14}$

\section{Underrepresented in policy spheres}

As the UK begins "learn to live with covid," there has been welcome funding allocated for increased resources to improve children and young people's access to mental health support, improve the home learning environment in the context of covid-19, increase physical activity, improved access to green spaces and improve nutrition, with some mention of prioritising those with a disability. ${ }^{15}$ However, these plans for recovery are not ambitious enough compared to similar high-income countries. ${ }^{16}$ Policies such as the introduction of the "Behaviour Hub" programme introduced by the Department for Education are punitive, with a lack of focus on 
positive behaviour support, and do not address the needs of children with autism. ${ }^{17}$

\section{The way forward}

Children and young people with autism have not been adequately represented at a policy level during the pandemic which has led to health services lacking the responsiveness to be tailored to meet the unique physical, mental, and emotional health needs of this vulnerable group. Supporting children and young people with autism is likely to increase their independence and future life course and economic prospects, hence benefitting the nation. It is important for this group of children and their families that a holistic view is adopted, integrating resources towards not only physical health, but also towards their mental and emotional health, as well as their access to additional support in education. A voice is needed to represent these children and young people in government, which will not only benefit them, but will benefit us as a society.

Competing Interests: none declared.

Provenance and peer review: Not commissioned, not peer reviewed

Acknowledgments: We would like to acknowledge support from the National Institute for Health Research (NIHR) through the National School for Public Health Research Programme and the Applied Health Research (ARC) programme for North West London.

$1 \quad$ BMJ. Autism spectrum disorder - Symptoms, diagnosis and treatment. BMJ Best Practice. 2021 https://bestpractice.bmj.com/topics/en-gb/379

2 Simonoff E, Pickles A, Charman T, Chandler S, Loucas T, Baird G. Psychiatric disorders in children with autism spectrum disorders: prevalence, comorbidity, and associated factors in a population-derived sample. J Am Acad Child Adolesc Psychiatry 2008;47:921-9. https://pubmed.ncbi.nlm.nih.gov/18645422/. doi: 10.1097/CHI.0b013e318179964f pmid: 18645422

3 O'Sullivan K, Clark S, McGrane A, etal. A Qualitative Study of Child and Adolescent Mental Health during the COVID-19 Pandemic in Ireland. Int J Environ Res Public Health 2021;18:1062. https://www.mdpi.com/1660-4601/18/3/1062. doi: 10.3390/ijerph18031062 pmid: 33504101

4 Paulauskaite L, Farris O, Spencer HM. Group E-I, Hassiotis A. My Son Can't Socially Distance or Wear a Mask: How Families of Preschool Children with Severe Developmental Delays and Challenging Behavior Experienced the COVID-19 Pandemic. J Ment Health Res Intellect Disabil 2021;14:225-36. https://www.tandfonline.com/action/journallnformation?journalCode=umid20doi: 10.1080/19315864.2021.1874578.

5 Ambitious about Autism. Autistic children facing mental health crisis during lockdown | Ambitious about Autism. 2021. https://www.ambitiousaboutautism.org.uk/about-us/media-centre/news/autistic-children-facing-mental-health-crisis-during-lockdown

6 Mutluer T, Doenyas C, Aslan Genc H. Behavioral Implications of the Covid-19 Process for Autism Spectrum Disorder, and Individuals' Comprehension of and Reactions to the Pandemic Conditions. Front Psychiatry 2020;11:561882. https://www.frontiersin.org/articles/10.3389/fpsyt.2020.561882/full. doi: 10.3389/fpsyt.2020.561882 pmid: 33304279

7 Statistics » Children and Young People with an Eating Disorder Waiting Times. https://www.england.nhs.uk/statistics/statistical-work-areas/cyped-waiting-times/

8 Dovey TM, Kumari V, Blissett JMealtime Hostage Parent Science Gang. Eating behaviour, behavioural problems and sensory profiles of children with avoidant/restrictive food intake disorder (ARFID), autistic spectrum disorders or picky eating: Same or different?Eur Psychiatry 2019;61:56-62. https://pubmed.ncbi.nlm.nih.gov/31310945/. doi: 10.1016/j.eurpsy.2019.06.008 pmid: 31310945

9 Nonweiler J, Rattray F, Baulcomb J, Happé F, Absoud M. Prevalence and Associated Factors of Emotional and Behavioural Difficulties during COVID-19 Pandemic in Children with Neurodevelopmental Disorders. Child 2020, Vol 7, Page 128. 2020 Sep 4;7(9):128. Available from: https://www.mdpi.com/2227-9067/7/9/128/htm

10 Covid could be leaving thousands with undiagnosed autism as uncertainty makes life harder for those on the spectrum - Manchester Evening News. Available from: https://www.manchestereveningnews.co.uk/news/greater-manchester-news/covid-could-leaving-thousands-undiagnosed-19304165

11 Maenner MJ, Shaw KA, Baio J, et al. Prevalence of Autism Spectrum Disorder Among Children Aged 8 Years - Autism and Developmental Disabilities Monitoring Network, 11 Sites, United States, 2014. MMWR Surveill Summ. 2018 Apr 27;67(6):1-23. doi: 10.15585/mmwr.ss6706a1

12 Rickard W, Donkin A. A social determinants of health approach to improving the lives and health of people with learning disabilities. CONTENTS: www.instituteofhealthequity.org

13 Left stranded: our new report into the impact of coronavirus. https://www.autism.org.uk/whatwe-do/news/coronavirus-report

14 Children and Young People Now. Three quarters of schools struggling to support SEND children during Covid lockdown | CYP Now. 2021 https://www.cypnow.co.uk/news/article/three-quartersof-schools-struggling-to-support-send-children-during-covid-lockdown
15 Department of Health and Social Care. Cabinet Office. COVID-19 mental health and wellbeing recovery action plan - GOV.UK. https://www.gov.uk/government/publications/covid-19-mentalhealth-and-wellbeing-recovery-action-plan/covid-19-mental-health-and-wellbeing-recovery-actionplan\#backing-the-nhs-ensuring-services-are-there-for-those-who-need-them

16 Siddique H. Guardian. Covid catch-up plan for England pupils 'pitiful compared with other countries'. https://www.theguardian.com/education/2021/jun/02/union-criticises-pitiful-covidcatch-up-plan-england-pupils

17 Department for Education. Behaviour hubs - GOV.UK 2020 https://www.gov.uk/guidance/behaviour-hubs\#overview 